\title{
Article \\ Short Term Caloric Restriction and Biofeedback Enhance Psychological Wellbeing and Reduce Overweight in Healthy Women
}

\author{
Alexander Kautzky ${ }^{1}$ D, Kathrin Heneis ${ }^{2,3}$, Karin Stengg ${ }^{4}$, Sabine Fröhlich ${ }^{4}$ and Alexandra Kautzky-Willer ${ }^{2,3, *(\mathbb{D})}$ \\ 1 Department of Psychiatry and Psychotherapy, Medical University of Vienna, 1090 Vienna, Austria; \\ alexander.kautzky@meduniwien.ac.at \\ 2 Department of Internal Medicine III, Division of Endocrinology and Metabolism, Medical University of \\ Vienna, 1090 Vienna, Austria; kathrin.heneis@meduniwien.ac.at \\ 3 Gender Institute, 3571 Gars am Kamp, Austria \\ 4 "La Pura" Womens Health Resort, 3571 Gars am Kamp, Austria; stengg@lapura.at (K.S.); \\ froehlich@lapura.at (S.F.) \\ * Correspondence: alexandra.kautzky-willer@meduniwien.ac.at
}

\section{check for} updates

Citation: Kautzky, A.; Heneis, K.; Stengg, K.; Fröhlich, S.; KautzkyWiller, A. Short Term Caloric Restriction and Biofeedback Enhance Psychological Wellbeing and Reduce Overweight in Healthy Women. J. Pers. Med. 2021, 11, 1096. https:// doi.org/10.3390/jpm11111096

Academic Editors: Alfredo De Giorgi, Rosaria Cappadona, Valeria Raparelli and Roberto Manfredini

Received: 24 September 2021

Accepted: 21 October 2021

Published: 26 October 2021

Publisher's Note: MDPI stays neutral with regard to jurisdictional claims in published maps and institutional affiliations.

Copyright: (c) 2021 by the authors. Licensee MDPI, Basel, Switzerland. This article is an open access article distributed under the terms and conditions of the Creative Commons Attribution (CC BY) license (https:/ / creativecommons.org/licenses/by/ $4.0 /)$.
Abstract: Obesity is highly prevalent, causing substantial cardiovascular and mental health morbidity. Women show increased risk for mental health disorders, that is multiplied in obesity and related to cellular and psychological stress that can be targeted by non-pharmacological interventions. A total of 43 women underwent two weeks of caloric restriction, half of which also received $7 \mathrm{~h}$ of individualized clinical psychological intervention including psychoeducation, mindfulness, and heart-rate-variability biofeedback. Effects on body mass index (BMI), fatty liver index (FLI), bioimpedance measures, serum parameters, perceived stress (PSS), burn-out susceptibility (burn out diagnostic inventory) and dimensional psychiatric symptom load (brief symptom inventory, BSI) were analyzed with linear mixed effects models. Caloric restriction led to a reduction in BMI, body fat and FLI, decreased serum concentrations of leptin, PSS score, BSI dimensions and global severity index (all $p \leq 0.0001$, withstanding Bonferroni-Holm correction). Benefits of add-on biofeedback were observed for BMI reduction $(p=0.041)$. Caloric restriction was effective in ameliorating both psychological wellbeing and metabolic functions following a BMI reduction. Biofeedback boosted effects on BMI reduction and the combinative therapy may be protective against common progression to mental health and cardiovascular disorders in overweight women while comparing favorably to pharmacological interventions in terms of side-effects and acceptability.

Keywords: obesity; caloric restriction; biofeedback; women's health; psychoneuroendocrinology; prevention; mental health

\section{Introduction}

Overweight and obesity are becoming increasingly common and were estimated to affect respectively $40 \%$ and $10 \%$ of the global population in 2016 [1].

Overweight dramatically increases the risk for diabetes mellitus (DM) type 2 and other metabolic and cardiovascular disorders [2]. Similar to other chronic diseases such as mental health disorders, prescribing medication has been demonstrated to be deficient to reach satisfactory outcomes for many patients [3].

Many psychiatric disorders, including the most common affective and anxiety disorders, are considerably more prevalent in women [4]. Furthermore, women are known to be more exposed to stressors and morbidity than men, making them a risk-population in both metabolic and mental health that may benefit most from preventive measures [5].

Associations between obesity and mental health disorders are increasingly adopted by clinicians in both psychiatry and endocrinology [6-8]. Biological links range from subclinical inflammation and molecular interplay between insulin and neurotransmitters 
to shared unfavorable genetic, epigenetic and metabolomic risk. Excessive body fat is known to cause subclinical inflammation and hypothalamic-pituitary-adrenal axis (HPA) dysregulations are known to occur early on in obese patients [9]. The HPA, predominantly regulating the biological stress response by hormones such as cortisol, plays a key role in both endocrine and mental health [10]. However, the contribution of psychosocial factors is also evident. Suffering from core symptoms of depression such as reduced energy clearly increases the risk for adopting an unfavorable lifestyle with low levels of physical activity and reduced self-care that brings along a higher risk for obesity.

Despite effective treatment options available for both, metabolic and mental health disorders, oftentimes symptom control is hard to achieve, and disease progression cannot be stopped [11,12]. In fact, up to a third of patients with major depressive disorder (MDD) does not reach sufficient improvement in symptoms within the first months of treatment and up to $15 \%$ can be expected to reach treatment resistance [13]. Importantly, integrative treatment protocols that aim at patient education and assistance in participation have shown promising results in both endocrine and psychiatric research [14,15].

Reducing psychological and biological stress and enhancing metabolism early on may be especially effective for disease prevention. Caloric restriction (CR) has recently been advocated for normalization of insulin sensitivity and glycemic control [16-18]. Furthermore, positive effects on mood and cognitive performance were proposed $[19,20]$, putatively mediated through enhancement of neuronal plasticity [21].

Similarly, biofeedback is a promising non-invasive tool to ameliorate both mental health and cardiometabolic dysfunction. Reduced heat rate variability (HRV) is a recognized feature of MDD [22], indicating impaired cardiac adaptation to new stimuli and stress [23]. Interventions aimed at increasing HRV have just recently been added to antidepressant protocols, mostly as an augmentation to cognitive behavioral psychotherapy [24-26].

\section{Materials and Methods}

\subsection{Sample}

Baseline characteristics and the recruitment protocol of the sample were described before [27], and details concerning all parameters included in analyses are provided in Supplementary Table S1. In short, women above 18 years of age were recruited at the VAMED gender institute (https:/ /www.vamed.com/en/company/gender-institute/, last accessed on 20 October 2021) in cooperation with the "Gender Medicine Unit" of the Medical University of Vienna between 2019 and 2020. In total, 43 women (mean age $53.42 \pm 11.7$ ) interested in a combined psychological and diet intervention tailored for stress reduction and achieving a healthier body composition were assessed by trained clinicians and psychologists during a stay at the "La Pura Women's Health Resort" (https: / www.lapura.at/, last accessed on 20 October 2021). All women were screened clinically for eating disorders by trained healthcare staff of the "La Pura" Women's Health Resort and all participants showed a BMI above the 25th percentile of the normal range $(>20)$ at participation, Participants had to be not currently pregnant and screened negative for any severe or chronic illness other than obesity, hypertension, and metabolic syndrome. As described before [27], none of the women had diabetes. A total of $7 \%$ of women showed metabolic syndrome according to the definition of the world diabetes federation, requiring the presence of central adiposity together with any two of the risk factors triglycerides: $\geq 150 \mathrm{mg} / \mathrm{dL}, \mathrm{HDL}$ cholesterol $<50 \mathrm{mg} / \mathrm{dL}$, blood pressure $\geq 130$ systolic or $85 \mathrm{mmHg}$ diastolic, respectively, or fasting plasma glucose $\geq 100 \mathrm{mg} / \mathrm{dL}$ [28]. None of the women had a diagnosis of liver disease. All subjects consented to the study procedures after having received detailed oral and written education. The study and all related measures were approved by the responsible Ethics Committee. 


\subsection{Treatment Groups}

Women were subsequently randomly allocated to two groups, receiving either (1) caloric restriction of either F.X. Mayr or very-low calorie diet (VLCD), or (2) caloric restriction and a clinical psychological intervention (CPI) (Figure 1).

\section{Stay at the "la pura" women's health resort}

\section{Day 1 \\ Baseline \\ Assessment of: \\ 1) Serum Parameters \\ Glucose Metabolism \\ Insulin Trafficking \\ Lipids, Liver Function \\ Adipokines}

\section{2) Anthropometry \\ BMI, WHtR, \\ Lean Mass, Body Fat, \\ Fatty Liver Index}

\section{3) Biofeedback}

HRV, Muscle Tone

\section{4) Psychometry BSI, PSS, BODI}

\section{Diet}

F.X. Mayr (700 - 800 kcal)
VLCD (700 kcal)

$$
\text { CPI (7 × } 50 \mathrm{~min})
$$

$2 \times$ Psychoeducation

$2 \times$ Mindfullness

$3 \times$ Biofeedback

ad libidum usage

of other offers

of the facility
Day 14

Final Visit

Assessment of:

1) Serum Parameters

2) Antrophometry

3) Biofeedback

4) Psychometry

Figure 1. Timeline and rationale of the study design. Additional offers provided by the facility included sport programs, balneotherapy and massages, and were not restricted by the study protocol. Abbreviations: CPI = clinical-psychological intervention, $\mathrm{VLCD}$ = very-low-calorie diet, $\mathrm{BMI}=$ body mass index, BSI = brief symptom inventory, PSS = perceives stress scale, BODI = burnout dimensions inventory.

The CPI consisted of seven sessions with a trained clinical psychologist that included two individualized psycho-educative talks regarding stress prevention, two sessions of Jacobson muscle relaxation and mindfulness training, and three sessions of biofeedback. Each session lasted $50 \mathrm{~min}$ and sessions were appointed over a time frame of 14 days. Biofeedback sessions aimed at controlling and improving biological functions, such as breathing rhythm, pulse, and blood pressure, with a focus on HRV. Serving as a proxy marker of emotional regulation that can be measured and displayed in real-time, HRV is directly targeted during biofeedback training by relaxation and breathing exercises.

The group without CPI, receiving only caloric restriction, was invited to a 50-min lecture on stress prevention held by a trained clinical psychologist and was free to choose from the repertoire of wellness and health-focused activities provided by the "La Pura" Women's Health Resort at the time of stay. Unrelated to the study protocol, these offers included sport programs, balneotherapy and massages.

VLCD restricts calorie intake to $630-700 \mathrm{kcal}$ per day split upon three meals. Following the protocol of Taylor et al. [17], carbohydrates, fat and proteins were reduced in equal 
measure to normalize glycemic control and enhance long-term weight loss ( $20 \%$ fat, $34 \%$ protein, $46 \%$ carbohydrates).

F.X. Mayr diet similarly applies calorie restriction to 700-800 kcal per day, however, is not primarily designed to reduce weight [29]. Instead, F.X. Mayr diet aims at stimulating gastrointestinal peristaltic and the production of bile acids and reducing daily insulin peaks. This is achieved by dietary rules such as prolonged chewing at a slower pace, food combining [30] and no food intake later than 7 p.m., together with calorie reduction and daily ingestion of isotonic magnesium sulfate solution.

All women were asked to document physical activity during their stay at the "La Pura" Women's Health Resort to allow calculation of the metabolic equivalent of task (MET) [31]. For each subject, physical activity during the study period was estimated by summed METs.

\subsection{Measures}

Anthropomorphic parameters and serum parameters were measured at baseline and after the study period of 14 days. Body mass index (BMI), waist circumference, body fat and lean mass assessed by bioelectric impedance analysis, as well as the waist-to-height-ratio (WHtR) were registered.

Serum parameters included cholesterol (HDL and total), triglycerides, sex hormones (testosterone, estradiol, follicle stimulating hormone (FSH) and luteinizing hormone (LH)), adipokines (leptin, secretagogin, resistin and adiponectin), alkaline phosphatase (AP), gamma glutamyltransferase (GGT), the pro-form of brain natriuretic peptide (proBNP), immuno-inflammatory markers c-reactive protein (CRP) and interleukin-6, and serum as well as saliva cortisol. Liver function and risk for non-alcoholic fatty liver disease (NAFLD) was primarily assessed by fatty liver index (FLI) that was calculated from triglycerides and GGT [31].

For assessment of serum brain-derived neurotrophic factor (BDNF) levels, the BioVendor ${ }^{\circledR}$ human BDNF ELISA kit was applied (BioVendor, Brno, Czech Republic). In more detail, plasma was collected at 08:00 in the morning after overnight fasting and probes were frozen at $-20^{\circ} \mathrm{C}$ before processing. All preparations, assay procedures and $\mathrm{BDNF}$ calculation were performed according to the product manual.

In addition, all subjects were analyzed by bio-feedback assessment using the NeXus 10 from MindMedia (6049 CD Herten, Netherlands, www.mindmedia.com/de/produkte/ nexus-10-mkii/, last accessed on 20 October 2021). Biofeedback parameters were assessed in a resting state at baseline (20 $\mathrm{min})$ as well as during stress exercises. These consisted of three consecutive stress tests (Stroop test [32], serial sevens [33], thinking of recent personal stressful experience) of three minutes each that were separated respectively by one minute of relaxation paradigms (looking at a relaxing image). HRV at baseline and under stress and systolic and diastolic blood pressure were used for analyses.

Psychometric assessment was also performed at baseline and at Day 14 of the study period. Thereby, the brief symptom inventory (BSI) was applied. The BSI provides a symptom score for psychiatric symptom dimensions as well as a global severity index (GSI) [34]. For assessment of burnout, the recently developed "burnout dimensions inventory" (BODI) was applied [35], composed of self-rating scores for the subitems of work, family and self-oriented stress as well as four composite items describing reduced resilience, reduced ability of distancing, depression and dysfunctional decompensation. Stress was also evaluated by the perceived stress scale [36].

A full characterization of all parameters by study visit and group can be found in Supplementary Table S1.

\subsection{Statistical Analyses}

Linear mixed models were computed with the statistical software " $R$ " (https:/ / www. r-project.org/, last accessed on 20 October 2021) applying the "nlme" package [37]. Each model was computed with the interaction term group * visit, therefore including the two- 
way interaction between treatment group (binomial) and visit (binomial; Day 1 and Day 14) as well as respective main fixed effects and patient identifier as random effect. Deviance tables were generated with the ANOVA function for "nlme" and respective F- and $p$-values are reported.

Results were corrected by Bonferroni-Holm test. Consequently, a $p$-value below a threshold of 0.0005 was required to withstand correction. Uncorrected $p$-values are reported and findings that did not withstand correction are referred to as trends.

\section{Results}

\subsection{Anthropomorphic Parameters}

Groups did not differ in glucose levels, $\mathrm{HbA} 1 \mathrm{c}$ and functional parameters for insulin sensitivity (Matsuda Index) or resistance (HOMA-IR) at baseline. A total of $67.4 \%$ of women scored above a BMI of 25, with $46.5 \%$ and $20.9 \%$ of women classified as overweight and obese, respectively. Further, $42.9 \%$ of obese women scored a BMI above 40 , indicating Obesity Grade III. Baseline BMI ranged from 20 to $42.9 \mathrm{~kg} / \mathrm{m}^{2}$.

BMI was significantly lower after the study period $(\mathrm{F}=89.3, p<0.0001)$. An interaction effect between time and CPI was observed, that did not withstand correction for multiple testing $(\mathrm{F}=4.4, p=0.041)$. Average BMI reduction was $0.67 \mathrm{~kg} / \mathrm{m}^{2}$ in women without CPI and $1.1 \mathrm{~kg} / \mathrm{m}^{2}$ in the women with add-on CPI. Physical activity during the study period was higher in women without $\mathrm{CPI}(\mathrm{F}=4.82, p=0.036)$.

Lower scores for WHtR $(\mathrm{F}=43.5, p<0.0001)$ and body fat $(\mathrm{F}=49.8, p<0.0001)$ were observed after the study period and a trend was observed for decreased lean mass $(\mathrm{F}=5.3$, $p=0.031$.

At baseline, $23.3 \%$ of patients showed a high risk for suffering from NAFLD, as indicated by a FLI $>60$. During the study period, the FLI declined in both groups $(\mathrm{F}=18$, $p=0.0001$ ), and $14 \%$ of patients scored a FLI $>60$ after two weeks of CR.

Please refer also to (Table 1, Section A) and Figure 2.

Table 1. Mixed model results, grouped by types of outcome parameters. For each outcome of interest, models with main effects of visit (baseline and after two weeks) and group (caloric restriction alone, and in combination with clinicalpsychological intervention-CPI), as well as their interaction effect were calculated. Only significant effects are listed. Numerator and denominator degrees of freedom (numDF, denDF), F and $p$-values are reported. Effects of visit indicate similar results in both treatment groups and thus caloric restriction. Uncorrected results are displayed. Interaction effects are indicated by *.

\begin{tabular}{cccccc}
\hline Outcome & Predictor & numDF & denDF & F-Value & $p$-Value \\
\hline & (A) Anthropometric Parameters & & & \\
\hline \multirow{2}{*}{ Body Mass Index } & Visit & 1 & 39 & 87.990 & $<0.0001$ \\
\cline { 2 - 6 } & Visit ${ }^{*}$ CPI & 1 & 41 & 4.4 & 43.5 \\
\hline Waist-to-Height Ratio & Visit & 1 & 40 & 36.6 & $<0.0001$ \\
\hline Waist Circumference & Visit & 1 & 38 & 49.8 & $<0.0001$ \\
\hline Body Fat & Visit & 1 & 21 & 5.3 & 0.031 \\
\hline Lean Mass & Visit & 1 & 22 & & 18 \\
\hline Fatty Liver Index & Visit & 1 & 39 & 0.0001 \\
\hline
\end{tabular}


Table 1. Cont.

\begin{tabular}{|c|c|c|c|c|c|}
\hline Outcome & Predictor & numDF & denDF & F-Value & $p$-Value \\
\hline \multicolumn{6}{|c|}{ (B) Serum and Biofeedback Parameters } \\
\hline Total Cholesterol & Visit & 1 & 40 & 7.1 & 0.011 \\
\hline HDL & Visit & 1 & 40 & 25.3 & $<0.0001$ \\
\hline Testosterone & Visit & 1 & 39 & 4.5 & 0.04 \\
\hline FSH & Visit & 1 & 39 & 27.1 & $<0.0001$ \\
\hline $\mathrm{AP}$ & Visit & 1 & 39 & 33.6 & $<0.0001$ \\
\hline Gamma GT & Visit & 1 & 39 & 16.7 & 0.0002 \\
\hline proBNP & Visit & 1 & 39 & 5.5 & 0.024 \\
\hline Adiponectin & Visit & 1 & 38 & 5 & 0.032 \\
\hline Secretagogin & Visit & 1 & 34 & 7.1 & 0.012 \\
\hline Leptin & Visit & 1 & 38 & 56.4 & $<0.0001$ \\
\hline Systolic Blood Pressure & Visit & 1 & 40 & 12.7 & 0.001 \\
\hline \multicolumn{6}{|c|}{ (C) Psychometric Parameters } \\
\hline PSS & Visit & 1 & 31 & 16.1 & 0.0003 \\
\hline BODI 3 & Visit & 1 & 29 & 10.2 & 0.003 \\
\hline GSI & Visit & 1 & 41 & 52.8 & $<0.0001$ \\
\hline Interpersonal Sensitivity & Visit & 1 & 41 & 24.5 & $<0.0001$ \\
\hline Somatization & Visit & 1 & 41 & 6.9 & 0.012 \\
\hline Depression & Visit & 1 & 41 & 25.1 & $<0.0001$ \\
\hline Anxiety & Visit & 1 & 41 & 30 & $<0.0001$ \\
\hline Aggression & Visit & 1 & 41 & 21.1 & 0.0001 \\
\hline Compulsion & Visit & 1 & 41 & 25.4 & $<0.0001$ \\
\hline Paranoia & Visit & 1 & 41 & 35.7 & $<0.0001$ \\
\hline Psychoticism & Visit & 1 & 41 & 22.5 & $<0.0001$ \\
\hline Stress Self-Oriented (BODI Self-Rating) & Visit & 1 & 31 & 5.7 & 0.023 \\
\hline
\end{tabular}

\subsection{Serum and Biofeedback Parameters}

Leptin $(\mathrm{F}=56.4, p<0.0001)$ and trendwise also adiponectin $(\mathrm{F}=5, p=0.032)$ and secretagogin $(\mathrm{F}=7.1, p=0.012)$ declined in all groups. Regarding sex hormones, an increase was observed for $\mathrm{FSH}(\mathrm{F}=27.1, p<0.0001)$ as well a trend of increased testosterone $(\mathrm{F}=4.5$, $p=0.04$ ).

Concerning cholesterol, strongest reductions were seen in HDL ( $\mathrm{F}=25.3, p<0.0001)$ while a trend was observed for total cholesterol $(\mathrm{F}=7.1, p=0.011)$. A reduction was also found in AP $(\mathrm{F}=33.6, p<0.0001)$ and GGT $(\mathrm{F}=16.7, p=0.0002)$ and on trend level for proBNP $(\mathrm{F}=5.31, p=0.027)$. No effects were found for BDNF, interleukin-6 and cortisol. Among biofeedback parameters, only the systolic blood pressure decreased on trend level $(\mathrm{F}=12.7, p=0.001)$.

Please refer also to Table 1, Section B. For graphical representations please see Figures 2 and 3.

\subsection{Psychometric Parameters}

At baseline, moderate self-perceived stress (PSSI $\geq 14$ ) was present in $67 \%$ of women. At day $14,54.5 \%$ of women showed low self-perceived stress ((PSSI $<14)$, leading to a significant reduction of PSS total scores across all groups $(\mathrm{F}=16.1, p=0.0003)$. Additionally, 
a trendwise reduction in BODI Item 3, reduced ability of distancing, was observed $(\mathrm{F}=10.2$, $p=0.003)$. Self-rating scores for as self-oriented stress was over time on trend level $(\mathrm{F}=5.7$, $p=0.023)$.
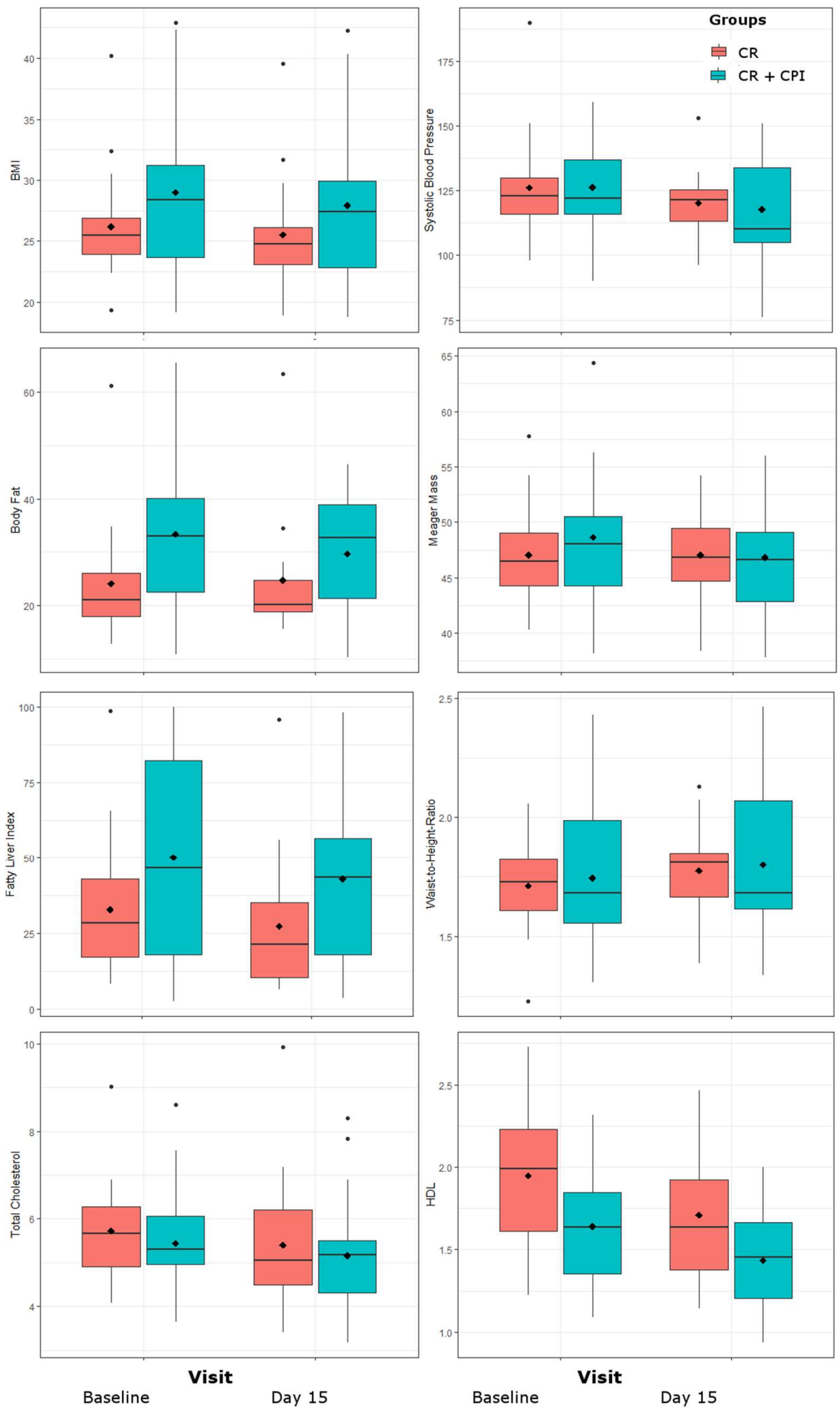

Figure 2. Changes in anthropometric parameters body mass index (BMI), waist-to-height-ratio, fatty liver index, as well as total and HDL cholesterol and systolic blood pressure over the study period of 14 days. Values are grouped by treatment groups of caloric restriction (CR) alone and CR together with clinical psychological intervention (CPI). 

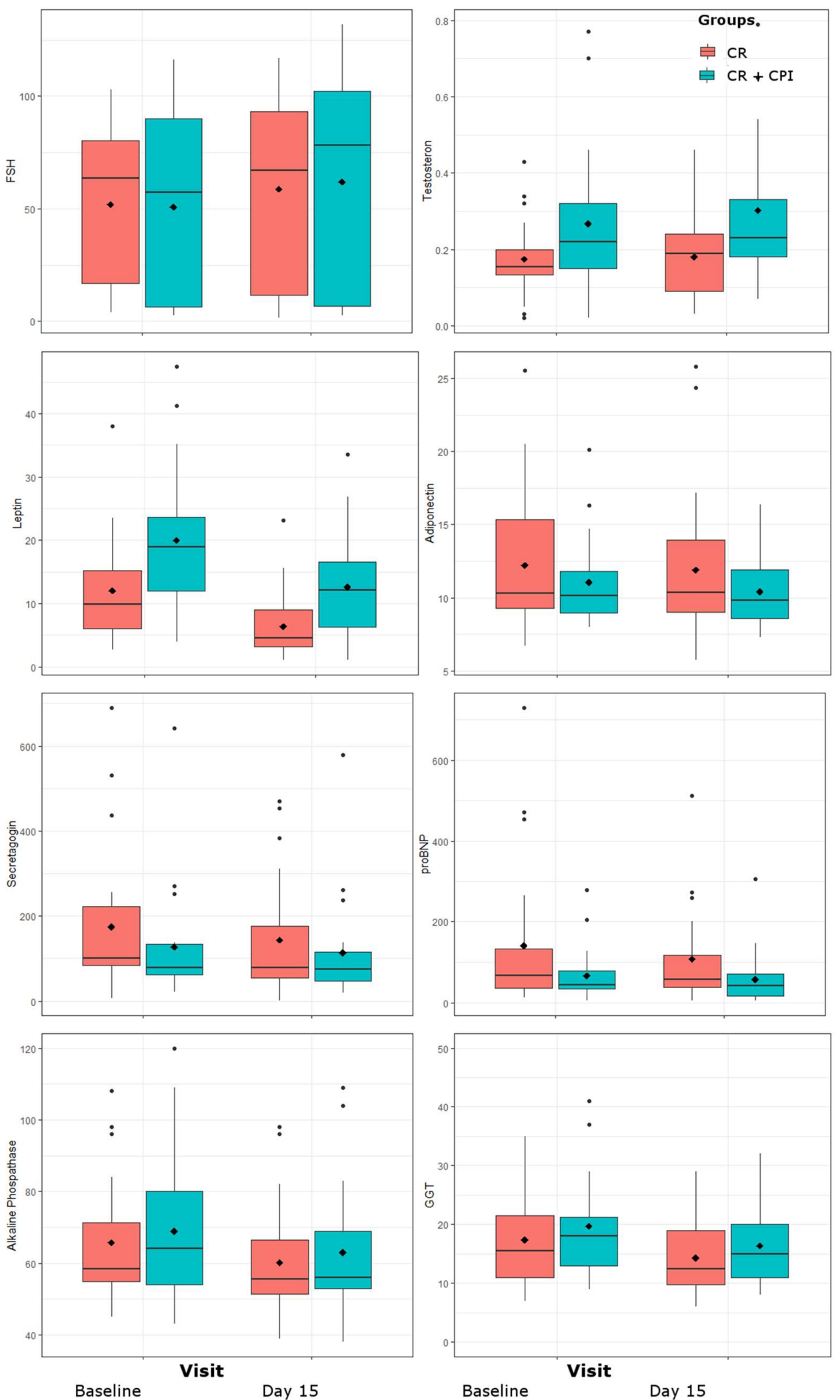

Figure 3. Changes in adipokines, sex hormones follicle-stimulating hormone (FSH) and testosterone, alkaline phosphatase, gamma-glutamyl-transferase (GGT) and pro-brain-natriuretic-peptide (proBNP) over the study period of 14 days. Values are grouped by treatment groups of caloric restriction (CR) alone and CR together with clinical psychological intervention (CPI). 
A decline in GSI ( $\mathrm{F}=52.8, p<0.0001)$ was observed, with clinically relevant scores (GSI $\geq 63$ ) in $32.5 \%$ of women at baseline and $4.7 \%$ of women at Day 14 . Similarly, BSI subscores for depression $(\mathrm{F}=25.1, p<0.0001)$, anxiety $(\mathrm{F}=30, p<0.0001)$, paranoia $(\mathrm{F}=35.7, p<0.0001)$, psychoticism $(\mathrm{F}=22.5, p<0.0001)$ compulsion $(\mathrm{F}=25.4, p<0.0001)$ and aggression $(\mathrm{F}=21.1, p=0.0001)$ declined, on trend level also somatization $(\mathrm{F}=6.9$, $p=0.012$ ).

Please refer also to Table 1, Section C. For graphical representations please see (Figure 4).
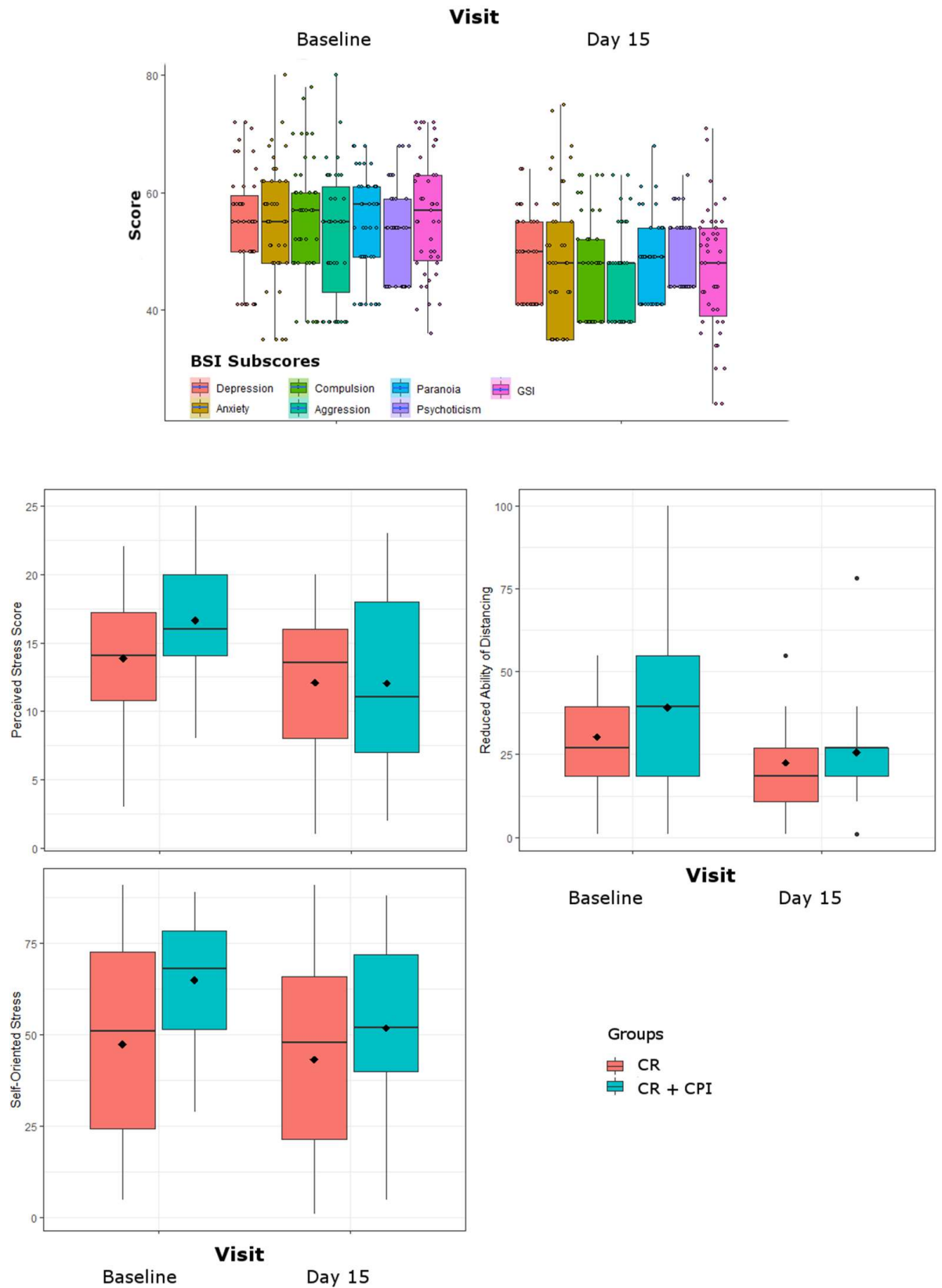

Figure 4. Changes in psychometric parameters over the study period of 14 days. Dimensional values of the brief symptom inventory (BSI) are provided for the two study timepoints as well as the global severity index (GSI). Results for the BODI Item 3 (reduced ability of distancing), the BODI self-rating of self-oriented stress and the perceived stress scale total score are grouped by treatment groups of caloric restriction (CR) alone and CR together with clinical psychological intervention (CPI). 


\section{Discussion}

Two weeks of CR showed favorable results concerning decrease in body fat and waist circumference, indicating reduced visceral fat that may represent metabolic adaptation protective of a broad range of diseases such as DM 2, cardiovascular and neurodegenerative events and oncologic disorders [38].

Other common findings after CR include changes in lipids, sex hormones and less consistently inflammation markers such as CRP [39,40]. Here, cholesterol parameters declined over the study period while CRP, cortisol and interleukin-6 did not show relevant changes. More surprisingly, we observed an increase in testosterone and FSH in all groups, contrasting earlier reports [41,42]. Considering the small sample size together with the short duration of the treatment period, rather favorable baseline values and the majority $(79 \%)$ of women being in peri- or post-menopause, changes in sex hormones and immunological markers should be interpreted cautiously.

Considering that obesity is a major risk factor for developing NAFLD, the general reduction of FLI after two weeks of CR is a promising finding. However, our data did not support significant effects of two weeks of CR and CPI on IL-6, which was suggested an important risk marker for NAFLD in obesity [43]. On the other hand, a mean reduction in IL-6 of $21 \%(p>0.05)$ was observed in those $23.3 \%$ of women who showed a high risk for presence of NAFLD. Consequently, protective effects may only be seen in a sample with more unfavorable clinical characteristics such as a high FLI or after longer CR protocols, which was suggested by some earlier studies [39]. Along these lines, despite a reported good specificity for FLI values $<30$ and sensitivity for values $>60$ for respective absence and presence of NAFLD, we cannot provide a definitive diagnosis since no further assessments such as sonography were performed [44]. Here, CR led to improvement of mental health, reflected by a decline in the BSI as well as perceived stress. Despite little data on CR in psychiatric treatment, a potential role of CR in affective disorders is a long standing but also timely finding $[19,45-47]$. Antidepressant qualities may be triggered by an adaptation to reduced glucose availability [20,48], leading to reduced radical oxygen species, increased lysosomal autophagy and changes in adipokines and mitochondrial functioning [49,50].

CR caused an average decrease of $33 \%$ in leptin concentrations. Leptin was shown to have direct neuroactive properties via leptin-receptors expressed in several brain regions [51,52]. Additionally, leptin extenuates overactivation of the HPA axis in rodent models. On the other hand, leptin also causes oxidative stress and most recent studies rather reported an increase in leptin concentration in depressed patients [53,54]. Despite leptin being reduced by $\mathrm{CR}$, both putatively stimulate neuroplasticity via similar pathways $[55,56]$. In rat models, CR but also leptin injections were shown to directly enhance neurogenesis and cell survival in the hippocampus, a well-established core region of structural and functional impairment in depression [57,58]. A possible solution may be leptin resistance in overweight patients and consequently a dissociation of leptin concentration from proper functioning [59]. The reduction of weight and leptin with concomitant amelioration of mental health in this study further strengthens a systemic role of leptin.

Consequently, CR shows overlap with the therapeutic mechanisms of commonly prescribed antidepressants and electro-convulsant therapy [60]. While we did not observe significant changes in BDNF levels, a lack of quick changes but rather increases after continuous treatment were also reported for non-rapid-acting antidepressants. Further, baseline differences between groups, with lower BDNF observed in the CPI groups compared to women receiving only dietary interventions $(\mathrm{F}=4.65, p=0.038)$, and a wide range of BDNF values with extreme values may hinder reliable interpretation.

$\mathrm{CR}$ findings in mental health are promising as most psychopharmacological agents bear a risk of weight gain and potentially deflect glucose metabolism to diabetogenic states [61]. Thus, dietary treatment options may be particularly helpful in overweight and obese patients, especially as early preventive measures. Good motivation for and adherence to self-administered CR regimens were reported at least in diabetic patients [62], addressing another decisive challenge in treatment of mental health disorders [14,15]. 
Augmentative effects of the add-on HRV-biofeedback and clinical-psychological intervention were less pronounced. While not reaching statistical significance, the recipients of CPI showed a greater mean decline over the study period for several stress related parameters such as BODI dysfunctional compensation (34.4\% vs. $25.7 \%)$ as well as PSS score ( $27.7 \%$ vs. $12.3 \%$ ). Interestingly, no changes in HRV could be detected between women having received CPI and those who did not. Previous integration of HRV biofeedback in MDD and anxiety patients mostly reported an increase in some functional parameters related to HRV [24]. However, the intervention applied here was considerably shorter compared to other studies on HRV biofeedback that usually implemented a training time of 6-10 weeks $[25,26,63,64]$. Similar to our result, a short intervention of just two weeks of biofeedback showed changes in HRV only in depressed patients but not healthy subjects, irrespective of mood changes [65]. Considering that all groups showed improvements in mental health dimensions, effects of CPI may be disguised by CR. Effects of CPI could also be influenced by between-group differences in physical activity that is beneficial for both metabolic and mental health. Considering that women without CPI had more time to spend on other activities, it may not be surprising that average physical activity was roughly $40 \%$ higher in these groups. In synopsis, the current results suggest a small add-on advantage of two weeks of CPI for BMI reduction.

Despite the Bonferroni-Holm correction, we cannot rule out false positive findings due to the small patient count and exploratory nature of the study. Results are reported in healthy women that mostly did not show clinically relevant deflections in either metabolic or psychometric parameters but still differed considerably in anthropo- and psycho-metric parameters, resulting in a high degree of heterogeneity. As a result, we were not able to further stratify the groups by implementing pre- or post-menopausal state in the analyses. Psychometric assessment was performed by a trained clinical psychologist; however, no psychiatric diagnostic interview was conducted. Further, while eating behavior was guided by the applied CR interventions, it was not formally assessed clinically or by dietary protocols. Considering that some dysfunctional eating behaviors were linked to symptoms of anxiety and depression as well as personality factors in the light of obesity [66], it may be important to control for these characteristics in future studies. Finally, women staying at the "La Pura" Women's Health Resort can be expected to show favorable socioeconomic status and therefore may not be representative of the general female population and general psychological effects mediated by the stay independently of the interventions must be assumed. This limitation is emphasized by the high education level of $87 \%$ of women reporting post-secondary education observed in this sample.

In synopsis, short-term CR and biofeedback in healthy women proved effective for reduction of psychological stress, mental health symptom load, as well as metabolic parameters. Differences between CR regimens and the benefit of add-on HRV biofeedback as well as long term changes in neurotrophic factors such as BDNF call for further investigation, especially in relevant patient groups with more severe deflections in metabolic and mental health. Nevertheless, our results advocate CR as a preventive tool for both metabolic and mental health disorders that compares favorably to pharmacological treatment in terms of relevant side effects and can easily be self-administered with little professional support $[26,62]$. Combined with reported high interest and good acceptability in the patient and at-risk groups, these non-pharmacological treatment options may substantially enrich the canon of preventive and augmentative treatment options in a broad spectrum of mental health and metabolic disorders, considering that obesity may be one the most critical moderating factor that can be reversed by patients themselves.

Supplementary Materials: The following are available online at https:/ / www.mdpi.com/article/ 10.3390/jpm11111096/s1, Table S1: Sample characteristics for all variables with means, standard deviations and number of data entries, respectively for visit 1 (V1, baseline) and visit 2 (V2, day 15). Characteristics are provided for the total sample as well as the two groups defined by either caloric restriction (CR) alone or with add-on clinical psychological intervention (CPI). 
Author Contributions: A.K. conducted data analysis and assisted study planning. K.H. was responsible for psychometric assessment and biofeedback as well as clinical-psychological interventions, primarily responsible for study planning and involved in preparation of the manuscript. K.S. and S.F. were responsible for clinical supervision of all subjects and contributed to the manuscript. A.K.-W. was responsible for study planning, manuscript preparation and supervision of all study-related procedures. All authors have read and agreed to the published version of the manuscript.

Funding: This research received no external funding.

Institutional Review Board Statement: All study-related procedures were approved by the responsible ethics committee, "Ethikkomission Niederösterreich" (GS1-EK-4/517-2017). All research was conducted ethically in accordance with the World Medical Association Declaration of Helsinki.

Informed Consent Statement: All subjects gave written consent to partaking in the study after thorough oral and written education about the study.

Data Availability Statement: Data are available from the corresponding author upon reasonable request.

Acknowledgments: We are thankful to all personnel of the Medical University of Vienna and the "La Pura" Women's Health Resort that assisted the study team.

Conflicts of Interest: The authors declare no conflict of interest.

\section{References}

1. Chooi, Y.C.; Ding, C.; Magkos, F. The epidemiology of obesity. Metabolism 2019, 92, 6-10. [CrossRef] [PubMed]

2. Carlsson, A.C.; Riserus, U.; Arnlov, J.; Borné, Y.; Leander, K.; Gigante, B.; Hellénius, M.-L.; Bottai, M.; de Faire, U. Prediction of cardiovascular disease by abdominal obesity measures is dependent on body weight and sex-Results from two community based cohort studies. Nutr. Metab. Cardiovasc. Dis. 2014, 24, 891-899. [CrossRef] [PubMed]

3. Yumuk, V.; Tsigos, C.; Fried, M.; Schindler, K.; Busetto, L.; Micic, D.; Toplak, H. European Guidelines for Obesity Management in Adults. Obes. Facts 2015, 8, 402-424. [CrossRef] [PubMed]

4. Anguzu, R.; Nagavally, S.; Dawson, A.Z.; Walker, R.J.; Egede, L.E. Age and Gender Differences in Trends and Impact of Depression on Quality of Life in the United States, 2008 to 2016. Womens Health Issues 2021, 31, 353-365. [CrossRef]

5. Mayor, E. Gender roles and traits in stress and health. Front. Psychol. 2015, 6, 779. [CrossRef] [PubMed]

6. Darwish, L.; Beroncal, E.; Sison, M.V.; Swardfager, W. Depression in people with type 2 diabetes: Current perspectives. Diabetes Metab. Syndr. Obes. 2018, 11, 333-343. [CrossRef]

7. Perry, B.I.; Mcintosh, G.; Weich, S.; Singh, S.; Rees, K. The association between first-episode psychosis and abnormal glycaemic control: Systematic review and meta-analysis. Lancet Psychiatry 2016, 3, 1049-1058. [CrossRef]

8. Moulton, C.D.; Pickup, J.C.; Ismail, K. The link between depression and diabetes: The search for shared mechanisms. Lancet Diabetes Endocrinol. 2015, 3, 461-471. [CrossRef]

9. Karczewski, J.; Sledzinska, E.; Baturo, A.; Jończyk, I.; Maleszko, A.; Samborski, P.; Begier-Krasińska, B.; Dobrowolska, A. Obesity and inflammation. Eur. Cytokine Netw. 2018, 29, 83-94. [CrossRef] [PubMed]

10. Joseph, J.J.; Golden, S.H. Cortisol dysregulation: The bidirectional link between stress, depression, and type 2 diabetes mellitus. Ann. N. Y. Acad. Sci. 2017, 1391, 20-34. [CrossRef] [PubMed]

11. Cipriani, A.; Furukawa, T.A.; Salanti, G.; Chaimani, A.; Atkinson, L.Z.; Ogawa, Y.; Leucht, S.; Ruhe, H.G.; Turner, E.H.; Higgins, J.P.T.; et al. Comparative efficacy and acceptability of 21 antidepressant drugs for the acute treatment of adults with major depressive disorder: A systematic review and network meta-analysis. Lancet 2018, 391, 1357-1366. [CrossRef]

12. American Diabetes Association. 2. Classification and Diagnosis of Diabetes: Standards of Medical Care in Diabetes-2021. Diabetes Care 2021, 44, S15-S33. [CrossRef] [PubMed]

13. Bartova, L.; Dold, M.; Kautzky, A.; Fabbri, C.; Spies, M.; Serretti, A.; Souery, D.; Mendlewicz, J.; Zohar, J.; Montgomery, S.; et al. Results of the European Group for the Study of Resistant Depression (GSRD)-basis for further research and clinical practice. World J. Biol. Psychiatry 2019, 20, 427-448. [CrossRef] [PubMed]

14. Mcgovern, A.; Tippu, Z.; Hinton, W.; Munro, N.; Whyte, M.; DE Lusignan, S. Comparison of medication adherence and persistence in type 2 diabetes: A systematic review and meta-analysis. Diabetes Obes. Metab. 2018, 20, 1040-1043. [CrossRef]

15. Keyloun, K.R.; Hansen, R.N.; Hepp, Z.; Gillard, P.; Thase, M.E.; Devine, E.B. Adherence and Persistence Across Antidepressant Therapeutic Classes: A Retrospective Claims Analysis Among Insured, U.S. Patients with Major Depressive Disorder (MDD). CNS Drugs 2017, 31, 421-432. [CrossRef] [PubMed]

16. Steven, S.; Hollingsworth, K.G.; Al-Mrabeh, A.; Avery, L.; Aribisala, B.; Caslake, M.; Taylor, R. Very Low-Calorie Diet and 6 Months of Weight Stability in Type 2 Diabetes: Pathophysiological Changes in Responders and Nonresponders. Diabetes Care 2016, 39, 808-815. [CrossRef] [PubMed]

17. Steven, S.; Taylor, R. Restoring normoglycaemia by use of a very low calorie diet in long- and short-duration Type 2 diabetes. Diabet. Med. 2015, 32, 1149-1155. [CrossRef] [PubMed] 
18. Lim, E.L.; Hollingsworth, K.G.; Aribisala, B.S.; Chen, M.J.; Mathers, J.C.; Taylor, R. Reversal of type 2 diabetes: Normalisation of beta cell function in association with decreased pancreas and liver triacylglycerol. Diabetologia 2011, 54, 2506-2514. [CrossRef]

19. Fond, G.; Macgregor, A.; Leboyer, M.; Michalsen, A. Fasting in mood disorders: Neurobiology and effectiveness. A review of the literature. Psychiatry Res. 2013, 209, 253-258. [CrossRef] [PubMed]

20. Igwe, O.; Sone, M.; Matveychuk, D.; Baker, G.B.; Dursun, S.M. A review of effects of calorie restriction and fasting with potential relevance to depression. Prog. Neuropsychopharmacol. Biol. Psychiatry 2020, 110206. [CrossRef]

21. Zhang, Y.; Liu, C.; Zhao, Y.; Zhang, X.; Li, B.; Cui, R. The Effects of Calorie Restriction in Depression and Potential Mechanisms. Curr. Neuropharmacol. 2015, 13, 536-542. [CrossRef] [PubMed]

22. Kemp, A.H.; Quintana, D.S.; Gray, M.A.; Felmingham, K.L.; Brown, K.; Gatt, J.M. Impact of depression and antidepressant treatment on heart rate variability: A review and meta-analysis. Biol. Psychiatry 2010, 67, 1067-1074. [CrossRef] [PubMed]

23. Sgoifo, A.; Carnevali, L.; Alfonso Mde, L.; Amore, M. Autonomic dysfunction and heart rate variability in depression. Stress 2015, 18, 343-352. [CrossRef] [PubMed]

24. Tatschl, J.M.; Hochfellner, S.M.; Schwerdtfeger, A.R. Implementing Mobile, H.R.V. Biofeedback as Adjunctive Therapy During Inpatient Psychiatric Rehabilitation Facilitates Recovery of Depressive Symptoms and Enhances Autonomic Functioning ShortTerm: A 1-Year Pre-Post-intervention Follow-Up Pilot Study. Front. NeuroSci. 2020, 14, 738. [CrossRef] [PubMed]

25. Lin, I.M.; Fan, S.Y.; Yen, C.F.; Yeh, Y.C.; Tang, T.C.; Huang, M.F.; Liu, T.L.; Wang, P.W.; Lin, H.C.; Tsai, H.-Y.; et al. Heart Rate Variability Biofeedback Increased Autonomic Activation and Improved Symptoms of Depression and Insomnia among Patients with Major Depression Disorder. Clin. Psychopharmacol. NeuroSci. 2019, 17, 222-232. [CrossRef]

26. Economides, M.; Lehrer, P.; Ranta, K.; Nazander, A.; Hilgert, O.; Raevuori, A.; Gevirtz, R.; Khazan, I.; Forman-Hoffman, V.L. Feasibility and Efficacy of the Addition of Heart Rate Variability Biofeedback to a Remote Digital Health Intervention for Depression. Appl. Psychophysiol. Biofeedback 2020, 45, 75-86. [CrossRef]

27. Kautzky, A.; Heneis, K.; Stengg, K.; Fröhlich, S.; Kautzky-Willer, A. Biological and psychological stress correlates are linked to glucose metabolism, obesity and gender roles in women. Neuroendocrinology 2021, in press. [CrossRef] [PubMed]

28. Ford, E.S. Prevalence of the metabolic syndrome defined by the International Diabetes Federation among adults in the U.S. Diabetes Care 2005, 28, 2745-2749. [CrossRef] [PubMed]

29. Witasek, A. Diagnosis and therapy after Dr. F. X. Mayr. Komplement 1999, 6, 45-46.

30. Manz, F. History of nutrition and acid-base physiology. Eur. J. Nutr. 2001, 40, 189-199. [CrossRef] [PubMed]

31. Jette, M.; Sidney, K.; Blumchen, G. Metabolic equivalents (METS) in exercise testing, exercise prescription, and evaluation of functional capacity. Clin. Cardiol. 1990, 13, 555-565. [CrossRef] [PubMed]

32. Stroop, J.R. Studies of Interference in Serial Verbal Reactions; George Peabody College for Teachers: Nashville, TN, USA, 1935.

33. Manning, R.T. The serial sevens test. Arch. Intern. Med. 1982, 142, 1192. [CrossRef] [PubMed]

34. Derogatis, L.R.; Spencer, P.M. Brief Symptom Inventory (BSI): Administration, Scoring and Procedures Manual; National Computer Systems: Minneapolis, MN, USA, 1993.

35. Scheibenbogen, O.; Andorfer, U.; Kuderer, M.; Musalek, M. Prävalenz des Burnout-Syndroms in Österreich. Abschlussbericht Bundesministeriums für Arbeit, Soziales und Konsumentenschutz (BMASK). 2017. Available online: https: //www.ibe.co.at/redx/tools/mb_download.php/mid.yf80d30c02b4d51cd/Abschlussbericht_Psychische_und_physische_ Gesundheitsbeeintraechtigungen___.pdf (accessed on 20 October 2021).

36. Cohen, S.; Kamarck, T.; Mermelstein, R. A global measure of perceived stress. J. Health Soc. Behav. 1983, 24, 385-396. [CrossRef] [PubMed]

37. Pinheiro, J.; Bates, D.; Debroy, S.; Sarkar, D.; the R Core Team. Linear and Nonlinear Mixed Effects Models. $R$ Package Version 2021, 3, 1-89.

38. Most, J.; Redman, L.M. Impact of calorie restriction on energy metabolism in humans. Exp. Gerontol. 2020, 133, 110875. [CrossRef] [PubMed]

39. Most, J.; Tosti, V.; Redman, L.M.; Fontana, L. Calorie restriction in humans: An update. Ageing Res. Rev. 2017, 39, 36-45. [CrossRef] [PubMed]

40. Pittas, A.G.; Roberts, S.B.; Das, S.K.; Gilhooly, C.H.; Saltzman, E.; Golden, J.; Stark, P.C.; Greenberg, A.S. The effects of the dietary glycemic load on type 2 diabetes risk factors during weight loss. Obesity 2006, 14, 2200-2209. [CrossRef] [PubMed]

41. Ravussin, E.; Redman, L.M.; Rochon, J.; Das, S.K.; Fontana, L.; Kraus, W.E.; Romashkan, S.; Williamson, D.A.; Meydani, S.N.; Villareal, D.T.; et al. A 2-Year Randomized Controlled Trial of Human Caloric Restriction: Feasibility and Effects on Predictors of Health Span and Longevity. J. Gerontol. A Biol. Sci. Med. Sci. 2015, 70, 1097-1104. [CrossRef] [PubMed]

42. Cangemi, R.; Friedmann, A.J.; Holloszy, J.O.; Fontana, L. Long-term effects of calorie restriction on serum sex-hormone concentrations in men. Aging Cell 2010, 9, 236-242. [CrossRef] [PubMed]

43. Tarantino, G.; Citro, V.; Capone, D. Nonalcoholic Fatty Liver Disease: A Challenge from Mechanisms to Therapy. J. Clin. Med. 2019, 9, 15. [CrossRef] [PubMed]

44. Bedogni, G.; Bellentani, S.; Miglioli, L.; Masutti, F.; Passalacqua, M.; Castiglione, A.; Tiribelli, C. The Fatty Liver Index: A simple and accurate predictor of hepatic steatosis in the general population. BMC Gastroenterol. 2006, 6, 33. [CrossRef] [PubMed]

45. Heun, E. Therapeutic fasting. Med. Klin. 1956, 51, 947-949. [PubMed]

46. Rooth, G.; Carlstrom, S. Therapeutic fasting. Acta Med. Scand. 1970, 187, 455-463. [CrossRef] [PubMed] 
47. Suzuki, J.; Yamauchi, Y.; Horikawa, M.; Yamagata, S. Fasting therapy for psychosomatic diseases with special reference to its indication and therapeutic mechanism. Tohoku J. Exp. Med. 1976, 118, 245-259. [CrossRef]

48. Manchishi, S.M.; Cui, R.J.; Zou, X.H.; Cheng, Z.Q.; Li, B.J. Effect of caloric restriction on depression. J. Cell Mol. Med. 2018, 22, 2528-2535. [CrossRef] [PubMed]

49. Moore, M.N.; Shaw, J.P.; Ferrar Adams, D.R.; Viarengo, A. Anti-oxidative cellular protection effect of fasting-induced autophagy as a mechanism for hormesis. Mar. Environ. Res. 2015, 107, 35-44. [CrossRef] [PubMed]

50. Marx, W.; Lane, M.; Hockey, M.; Aslam, H.; Berk, M.; Walder, K.; Borsini, A.; Firth, J.; Pariante, C.M.; Berding, K.; et al. Diet and depression: Exploring the biological mechanisms of action. Mol. Psychiatry 2020. [CrossRef] [PubMed]

51. Fontana, L.; Klein, S.; Holloszy, J.O. Effects of long-term calorie restriction and endurance exercise on glucose tolerance, insulin action, and adipokine production. Age 2010, 32, 97-108. [CrossRef] [PubMed]

52. Zou, X.; Zhong, L.; Zhu, C.; Zhao, H.; Zhao, F.; Cui, R.; Gao, S.; Li, B. Role of Leptin in Mood Disorder and Neurodegenerative Disease. Front. NeuroSci. 2019, 13, 378. [CrossRef] [PubMed]

53. Hariri, M.A.; Jaffa, M.A.; Saoud, R.; Zhao, J.; Zhu, R.; Jaffa, A.A.; El-Achkar, G.A.; Moussa, M.; Kobeissy, F.; Hassan, A.; et al. Vascular Cells Proteome Associated with Bradykinin and Leptin Inflammation and Oxidative Stress Signals. Antioxidants 2020, 9 , 1251. [CrossRef]

54. Milaneschi, Y.; Sutin, A.R.; Terracciano, A.; Canepa, M.; Gravenstein, K.S.; Egan, J.M.; Vogelzangs, N.; Guralnik, J.M.; Bandinelli, S.; Penninx, B.W.; et al. The association between leptin and depressive symptoms is modulated by abdominal adiposity. Psychoneuroendocrinology 2014, 42, 1-10. [CrossRef] [PubMed]

55. Fusco, S.; Ripoli, C.; Podda, M.V.; Ranieri, S.C.; Leone, L.; Toietta, G.; McBurney, M.W.; Schütz, G.; Riccio, A.; Grassi, C.; et al. A role for neuronal cAMP responsive-element binding (CREB)-1 in brain responses to calorie restriction. Proc. Natl. Acad. Sci. USA 2012, 109, 621-626. [CrossRef] [PubMed]

56. Araya, A.V.; Orellana, X.; Espinoza, J. Evaluation of the effect of caloric restriction on serum BDNF in overweight and obese subjects: Preliminary evidences. Endocrine 2008, 33, 300-304. [CrossRef]

57. Xu, W.; Yao, X.; Zhao, F.; Zhao, H.; Cheng, Z.; Yang, W.; Cui, R.; Xu, S.; Li, B. Changes in Hippocampal Plasticity in Depression and Therapeutic Approaches Influencing These Changes. Neural Plast. 2020, 2020, 8861903. [CrossRef]

58. Zainuddin, M.S.; Thuret, S. Nutrition, adult hippocampal neurogenesis and mental health. Br. Med. Bull. 2012, 103, 89-114. [CrossRef] [PubMed]

59. Milaneschi, Y.; Lamers, F.; Bot, M.; Drent, M.L.; Penninx, B.W. Leptin Dysregulation Is Specifically Associated With Major Depression With Atypical Features: Evidence for a Mechanism Connecting Obesity and Depression. Biol. Psychiatry 2017, 81, 807-814. [CrossRef]

60. Polyakova, M.; Stuke, K.; Schuemberg, K.; Mueller, K.; Schoenknecht, P.; Schroeter, M.L. BDNF as a biomarker for successful treatment of mood disorders: A systematic \& quantitative meta-analysis. J. Affect. Disord. 2015, 174, 432-440. [PubMed]

61. Serretti, A.; Mandelli, L. Antidepressants and body weight: A comprehensive review and meta-analysis. J. Clin. Psychiatry 2010, 71, 1259-1272. [CrossRef]

62. Steven, S.; Lim, E.L.; Taylor, R. Population response to information on reversibility of Type 2 diabetes. Diabet. Med. 2013, 30, e135-8. [CrossRef]

63. Karavidas, M.K.; Lehrer, P.M.; Vaschillo, E.; Vaschillo, B.; Marin, H.; Buyske, S.; Malinovsky, I.; Radvanski, D.; Hassett, A. Preliminary results of an open label study of heart rate variability biofeedback for the treatment of major depression. Appl. Psychophysiol. Biofeedback 2007, 32, 19-30. [CrossRef] [PubMed]

64. Hartogs, B.M.A.; Bartels-Velthuis, A.A.; van der Ploeg, K.; Bos, E.H. Heart Rate Variability Biofeedback Stress Relief Program for Depression*. A Replicated Single-Subject Design. Methods Inf. Med. 2017, 56, 419-426. [PubMed]

65. Siepmann, M.; Aykac, V.; Unterdorfer, J.; Petrowski, K.; Mueck-Weymann, M. A pilot study on the effects of heart rate variability biofeedback in patients with depression and in healthy subjects. Appl. Psychophysiol. Biofeedback 2008, 33, 195. [CrossRef] [PubMed]

66. Gade, H.; Rosenvinge, J.H.; Hjelmesaeth, J.; Friborg, O. Psychological correlates to dysfunctional eating patterns among morbidly obese patients accepted for bariatric surgery. Obes. Facts 2014, 7, 111-119. [CrossRef] [PubMed] 